\title{
Adaptation of Nonlinear Mathematical Models to Take into Consideration the Date of Conception of Animal Species
}

\author{
Mohammed Balafrej \\ Department of Agriculture, Production Chains Development Directorate, Rabat, Morocco \\ Email address: \\ balafrejmed@hotmail.com \\ To cite this article: \\ Mohammed Balafrej. Adaptation of Nonlinear Mathematical Models to Take into Consideration the Date of Conception of Animal Species. \\ International Journal of Systems Science and Applied Mathematics. Vol. 4, No. 2, 2019, pp. 18-23. doi: 10.11648/j.ijssam.20190402.11
}

Received: August 23, 2019; Accepted: September 6, 2019; Published: September 21, 2019

\begin{abstract}
Nonlinear functions are of great interest in the field of livestock, particularly through the modeling of the relationship between weight and age in animal species, which facilitates both the interpretation and the understanding of the growth phenomenon. Adjustments to growth data allow the information to be condensed into a few parameters that are used for selection purposes and to improve production forecasts. However, these functions do not take into consideration the fixed nature of the conception date which is specific for each animal species. In principle, all observations should be based on this date. The purpose of this study is to adapt the most frequently used mathematical models to take into consideration the conception dates of animal species. To do this, four functions were studied namely those of Logistic, Gompertz, Richards and Von Bertalanffy. Afterwards, modified models were developed to determine their derivatives and inflection points. An example of an initial model and its adaptations were adjusted to the data of moroccan sheep "sardi" to observe the effects of adaptations on the growth curves for males and females of this species. The results obtained show that among these functions, only Richards and Von Bertalanffy could be adapted according to two methods to meet the aforementioned objective because the logistic and Gompertz models are strictly positive and do not cancel each other out. In addition, the comparison example between Richards' Model and its adaptations to sheep data shows that for the initial model, the conception dates are -24.07 days and -23.6 days for males and females, respectively. while modified models, whose adjustment results show similar results, have -150 day conception dates for both sexes. In conclusion, the modified models of Richards and Von Bertalanffy seem to represent at best the biology of animal species and therefore, could replace the initial models for future studies of animal species growth modeling.
\end{abstract}

Keywords: Logistic, Gompertz, Richards, Von Bertalanffy, Conception Date, Inflexion Point, Growth Model

\section{Introduction}

To model the relationship between weight and age, nonlinear functions such as Logistic, Gompertz, Richards and Von Bertalanffy are widely used around the world and for different animal species. These functions, adjusted to growth data, make it possible to determine parameters that can be used for selection purposes and to improve production forecasts by better managing the food calendar of the animal species used in breeding.

The growth curve is represented mathematically as a sigmoidal function, defined in a real line, bounded and differentiable with positive derivative. Its graph has a typical $\mathrm{S}$ shape showing slow growth at the beginning, followed by a fast (exponential) growth that slows down gradually until it reaches an equilibrium value (usually named carrying capacity or level of saturation) [1]. In biology, it is represented as a function of age and live weight, covering all or part of the life of the animal [2]. Growth can be defined as the weight gain of an animal until it reaches adulthood. In the early stages of life, this growth accelerates and the weight gain is greater than the approach of adulthood, producing a sigmoidal curve. After the inflection point, growth gradually decreases and the growth rate becomes slower and slower.

In animal biology, growth functions have been used mainly since the beginning of the 20th century. The key works in the development of this concept are those of Benjamin Gompertz in 1825 [3], that of Brody in 1945 [4] and Ludwig von Bertalanffy in 1957 [5].

The use of mathematical growth models provides a good 
way to condense information into a few biologically meaningful parameters, to facilitate both interpretation and understanding of the growth phenomenon [6-7]. This models provides several applications to animal production, such as the evaluation of the response to treatments as time goes by; analysis of the interaction between subpopulations (or treatments) and time and identification of heavier and younger animals in a population [8-9].

In livestock and poultry, the fitting and analysis of growth curves of parameters is the basic work for breeding and production. The growth curve parameters determination, effectively, describe issues such as growth, livestock performance, and optimum slaughter age, as well as preparing an appropriate feeding process and selection [10]. As for partridges, these parameters facilitate the judgment and analysis the standards of feeding, management and epidemic prevention, and to compare and test the genetic quality of different genders [11].

Nonlinear models describing body weight can be formulated as follows:

$$
Y i j=f\left(\beta_{i j}, u_{i j}\right)+\varepsilon_{i j}, \varepsilon_{i j} \sim N\left(0, \sigma^{2}\right)
$$

where Yij is the response value of the $\mathrm{j}^{\text {th }}$ observation of the individual $(i=1, \ldots, M, j=1, \ldots, n i) ; M$ is the total number of individuals, and ni is the number of observations for the $i^{\text {th }}$ individual; $\mathrm{f}$ is the nonlinear function linking body weight to age and other possible covariates $u_{i j}$ varying with the individual; $\beta_{\mathrm{ij}}$ is a vector with the parameters of the nonlinear function; $\varepsilon_{\mathrm{ij}}$ is the residual term; and $\sigma 2 \mathrm{e}$ is the variance for the residues [12].

The mathematical representation of growth functions and their properties is given in Table 1 .

Table 1. Mathematical description of growth patterns and the resulting biological parameters.

\begin{tabular}{|c|c|c|c|c|c|}
\hline Model name & Mathematical expression $f(t)$ & Expression of B & Inflexion Point & Inflexion Age & Growth rate f'(t) \\
\hline Logistic [13] & $\frac{A}{\left(1+B e^{-K t}\right)}$ & $\left(\frac{A}{A_{0}}\right)-1$ & $\frac{\mathrm{A}}{2}$ & $\frac{\ln B}{K}$ & $K f(t)\left(1-\frac{f(t)}{A}\right)$ \\
\hline Gompertz [14] & $\mathrm{A} \mathrm{e}^{-\mathrm{Be}}-\mathrm{Kt}$ & $\ln \left(\frac{A}{A_{0}}\right)$ & & $\frac{\ln B}{K}$ & $K f(t) \ln \left(\frac{A}{f(t)}\right)$ \\
\hline Richards [15] & $A\left(1-B e^{-K t}\right)^{M}$ & $1-\left(\frac{A_{0}}{A}\right)^{M}$ & $A\left(1-\frac{1}{M}\right)^{M}$ & $\frac{\ln M B}{K}$ & $\left.M K f(t)^{\left(1-\frac{1}{M}\right.}\right)\left(A^{\frac{1}{M}}-f(t)^{\frac{1}{M}}\right)$ \\
\hline Von bertalanffy [16] & $A\left(1-B e^{-K t}\right)^{3}$ & $1-\left(\frac{A_{0}}{A}\right)^{3}$ & $\frac{8}{27} \mathrm{~A}$ & $\frac{\ln 3 \mathrm{~B}}{\mathrm{~K}}$ & $3 \mathrm{Kf}(\mathrm{t})^{\frac{2}{3}}\left(\mathrm{~A}^{\frac{1}{3}}-\mathrm{f}(\mathrm{t})^{\frac{1}{3}}\right)$ \\
\hline
\end{tabular}

The biological interpretation of the parameters of these equations is as follows:

A0: the birth weight corresponding to $t=0$.

A: Adult or mature weight representing the asymptotic limit of each model, as age (t) approaches infinity. It is an asymptotic average weight [17].

$\mathrm{B}$ : The ordinate at the origin, describes the weight at time zero, which corresponds to the initial weight of the animal. This value is called the integration constant and has no biological interpretation;

$\mathrm{K}$ : The slope of the growth curve which is also a measure of the approximation rate for its asymptotic value and represents the postnatal maturation rate. A large value of $\mathrm{k}$ indicates an early maturity of the animal;

M: The determining parameter of the Richards model curve [18].

However, these functions do not take into account the date of conception $t_{i}$ which is located at the negative part of the abscissa axis corresponding to $\mathrm{f}(\mathrm{ti})=0$. This date, which is negative, corresponds in biology to the fertilization of the egg by the spermatozoon. In principle, all observations should have as a starting point this date of conception. The latter is approximately -150 days and -370 days respectively for sheep and cattle. If $t_{0}$ is the date of birth, the time between conception and birth $t_{0}$ - ti corresponds to the gestation period that is known per species. However, this data seems to be omitted when adjusting the data.

The functions of both Logistic and Gompertz models are always positive and never cancel each other out. Therefore, $t_{i}$ do not exist for these two functions and the models that seem to best reflect the reality are those of Richards and Von Bertalanffy.

Moreover, if $\mathrm{f}\left(\mathrm{t}_{\mathrm{i}}\right)=0$ and ti are known, we can adapt the equations of the models to each animal species and in this case, one of the two parameters, B or K, will be deduced from the other and consequently, removed from formulas. Subsequently, the growth rate corresponding to the derivative $\mathrm{f}^{\prime}(\mathrm{t})$ and the point of inflection corresponds mathematically to the point where the tangent crosses the curve and where there is a change in concavity. In this case, the second derivative $\mathrm{f}^{\prime \prime}(\mathrm{t})$ is cancelled by changing the sign. The age of inflection is deduced from the point of inflection ( $\mathrm{f}(\mathrm{t})=$ inflection point). In biology, it is advantageous to select the early animals that reach this point as quickly as possible.

\section{Adaptation of Models, Derivations and Inflection Points}

\subsection{Richards Function}

Richard's function is defined according to the following notation

$$
f(t)=A\left(1-B e^{-K t}\right)^{M}
$$

First adaptation of the model:

$$
\begin{gathered}
\mathrm{f}\left(\mathrm{t}_{\mathrm{i}}\right)=0 \leftrightarrow \mathrm{A}\left(1-\mathrm{B} \mathrm{e}^{-\mathrm{Kt} \mathrm{t}_{\mathrm{i}}}\right)^{\mathrm{M}}=0 \leftrightarrow 1-\mathrm{Be}^{-K \mathrm{t}_{\mathrm{i}}}=0 \\
\leftrightarrow \mathrm{e}^{-\mathrm{Kt_{i }}}=\frac{1}{\mathrm{~B}}
\end{gathered}
$$




$$
\mathrm{K}=\frac{\ln \mathrm{B}}{\mathrm{t}_{\mathrm{i}}}
$$

We replace $\mathrm{K}$ in the equation

$$
f(t)=A\left(1-B e^{-\frac{\ln B}{t_{i}} t}\right)^{M}
$$

Thus, the model can be written as

$$
f(t)=A\left(1-B^{1-\frac{t}{t_{i}}}\right)^{M}
$$

We can conclude that:

$$
\mathrm{B}^{1-\frac{\mathrm{t}}{\mathrm{t}_{\mathrm{i}}}}=1-\left(\frac{\mathrm{f}(\mathrm{t})}{\mathrm{A}}\right)^{\frac{1}{\mathrm{M}}}
$$

First derivation off $(\mathrm{t})$

$$
\begin{gathered}
f(t)=A y(t)^{M} \text { où } y(t)=1-B^{1-\frac{t}{t_{i}}}=1-B\left(B^{-\frac{1}{t_{i}}}\right)^{t}, \\
y^{\prime}(t)=\frac{\ln B}{t_{i}} B^{1-\frac{t}{t_{i}}}=\frac{\ln B}{t_{i}}\left[1-\left(\frac{f(t)}{A}\right)^{\frac{1}{M}}\right] .
\end{gathered}
$$

This implies that

$$
\begin{aligned}
& f^{\prime}(t)=A M y^{\prime}(t) y(t)^{M-1}= \\
& A M \frac{\ln B}{t_{i}}\left[1-\left(\frac{f(t)}{A}\right)^{\frac{1}{M}}\right]\left(\frac{f(t)}{A}\right)^{\left(1-\frac{1}{M}\right)} \text {, } \\
& \mathrm{f}^{\prime}(\mathrm{t})=\mathrm{AM} \frac{\ln \mathrm{B}}{\mathrm{t}_{\mathrm{i}}}\left[1-\left(\frac{\mathrm{f}(\mathrm{t})}{\mathrm{A}}\right)^{\frac{1}{\mathrm{M}}}\right]\left(\frac{\mathrm{f}(\mathrm{t})}{\mathrm{A}}\right)\left(\frac{\mathrm{f}(\mathrm{t})}{\mathrm{A}}\right)^{\frac{-1}{\mathrm{M}}}, \\
& f^{\prime}(t)=M \frac{\ln B}{t_{i}} f(t)\left[\left(\frac{f(t)}{A}\right)^{-\frac{1}{M}}-1\right],
\end{aligned}
$$

Therefore

$$
f^{\prime}(t)=M \frac{\ln B}{t_{i}}\left[A^{\frac{1}{M}} f(t)^{\left(1-\frac{1}{M}\right)}-f(t)\right]
$$

Second derivation of $\mathrm{f}(\mathrm{t})$

We have $f^{\prime}(t)^{\left(1-\frac{1}{M}\right)}=\left(\frac{M-1}{m}\right) f^{\prime}(t) f(t)^{-\frac{1}{M}}$ therefore,

$$
\begin{aligned}
f^{\prime \prime}(t)= & \frac{\ln B}{t_{i}} f^{\prime}(t)\left\{\left[(M-1) A^{\frac{1}{M}} f(t)^{-\frac{1}{M}}\right]-M\right\} . \\
f^{\prime \prime}(t)= & \frac{\ln B}{t_{i}} M \frac{\ln B}{t_{i}}\left[A^{\frac{1}{M}} f(t)^{\left(1-\frac{1}{M}\right)}-f(t)\right] \\
& \left\{\left[(M-1) A^{\frac{1}{M}} f(t)^{-\frac{1}{M}}\right]-M\right\} . \\
f^{\prime \prime}(t)= & M\left(\frac{\ln B}{t_{i}}\right)^{2}\left\{\left[(M-1) A^{\frac{2}{M}} f(t)^{\left(1-\frac{2}{M}\right)}\right]-[(2 M-\right. \\
& \left.\left.1) A^{\frac{1}{M}} f(t)^{\left(1-\frac{1}{M}\right)}\right]+M f(t)\right\}
\end{aligned}
$$

Calculation of the inflection point When

$$
\begin{gathered}
f^{\prime \prime}(t)=0 \leftrightarrow(M-1) A^{\frac{1}{M}} f(t)^{-\frac{1}{M}}-M=0 \leftrightarrow f(t)^{-\frac{1}{M}} \\
=\frac{M}{(M-1)} A^{\frac{1}{M}} .
\end{gathered}
$$

Therefore the inflection point is

$$
f(t)=A\left(1-\frac{1}{M}\right)^{M}
$$

Afterwards, we replace $f(t)$ by its formula to find the date corresponding to the inflexion point

$$
\mathrm{A}\left(1-\frac{1}{\mathrm{M}}\right)^{\mathrm{M}}=\mathrm{A}\left(1-\mathrm{B}^{1-\frac{\mathrm{t}}{\mathrm{t}_{\mathrm{i}}}}\right)^{\mathrm{M}} \leftrightarrow 1-\frac{1}{\mathrm{M}}=1-\mathrm{B}^{1-\frac{\mathrm{t}}{\mathrm{t}_{\mathrm{i}}} .}
$$

This implies that

$$
t=t_{i} \frac{\ln M B}{\ln B}
$$

Second adaptation of the model:

$$
\begin{gathered}
\mathrm{f}(\mathrm{t})=\mathrm{A}\left(1-\mathrm{B} \mathrm{e}^{-\mathrm{K} t}\right)^{\mathrm{M}} \\
\mathrm{f}\left(\mathrm{t}_{\mathrm{i}}\right)=0 \leftrightarrow \mathrm{A}\left(1-\mathrm{B} \mathrm{e}^{-\mathrm{Kt}_{\mathrm{i}}}\right)^{\mathrm{M}}=0 \leftrightarrow 1-\mathrm{Be}^{-\mathrm{Kt}_{\mathrm{i}}}=0 \\
\leftrightarrow \mathrm{B}=\mathrm{e}^{\mathrm{Kt_{ \textrm {i } }}}
\end{gathered}
$$

We replace $\mathrm{B}$ in the equation and the model can be written as follows

$$
f(t)=A\left(1-e^{-K\left(t-t_{i}\right)}\right)^{M}
$$

We can conclude that:

$$
e^{-K\left(t-t_{i}\right)}=1-\left(\frac{f(t)}{A}\right)^{\frac{1}{M}} .
$$

First derivation of $\mathrm{f}(\mathrm{t})$

$$
\begin{gathered}
f(t)=A y(t)^{M} \text { où } y(t)=1-e^{-K\left(t-t_{i}\right)} \\
y^{\prime}(t)=K e^{-K\left(t-t_{i}\right)}
\end{gathered}
$$

This implies that

$$
\begin{gathered}
f^{\prime}(t)=A M y^{\prime}(t) y(t)^{M-1} \\
=A M K^{-K\left(t-t_{i}\right)}\left(1-e^{-K\left(t-t_{i}\right)}\right)^{M-1} \\
f^{\prime}(t)=A M K\left[1-\left(\frac{f(t)}{A}\right)^{\frac{1}{M}}\right]\left(\frac{f(t)}{A}\right)^{1-\frac{1}{M}} . \\
f^{\prime}(t)=\text { A M K }\left[\left(\frac{f(t)}{A}\right)^{1-\frac{1}{M}}-\left(\frac{f(t)}{A}\right)\right] .
\end{gathered}
$$

Therefore

$$
f^{\prime}(t)=M K\left[A^{\frac{1}{M}} f(t)^{\left(1-\frac{1}{M}\right)}-f(t)\right]
$$

Second derivation of $\mathrm{f}(\mathrm{t})$ 


$$
\begin{aligned}
& f^{\prime \prime}(t)=M K\left\{\left[A^{\frac{1}{M}}\left(1-\frac{1}{M}\right) f^{\prime}(t) f(t)^{-\frac{1}{M}}\right]-f^{\prime}(t)\right\}, \\
& f^{\prime \prime}(t)=M K f^{\prime}(t)\left\{\left[\left(1-\frac{1}{M}\right) A^{\frac{1}{M}} f(t)^{-\frac{1}{M}}\right]-1\right\}, \\
& \mathrm{f}^{\prime \prime}(\mathrm{t})= \\
& M^{2} K^{2}\left[A^{\frac{1}{M}} f(t)\left(1-\frac{1}{M}\right)-f(t)\right]\left\{\left[\left(1-\frac{1}{M}\right) A^{\frac{1}{M}} f(t)^{-\frac{1}{M}}\right]-1\right\} .
\end{aligned}
$$

Therefore

$$
\begin{gathered}
f^{\prime \prime}(t)=M^{2} K^{2}\left\{\left[\left(1-\frac{1}{M}\right) A^{\frac{2}{M}} f(t)^{\left(1-\frac{2}{M}\right)}\right]-[(2-\right. \\
\left.\left.\left.\frac{1}{M}\right) A^{\frac{1}{M}} f(t)^{\left(1-\frac{1}{M}\right)}\right]+f(t)\right\}
\end{gathered}
$$

Calculation of the inflection point

When

$$
\begin{gathered}
f^{\prime \prime}(t)=0 \leftrightarrow\left(1-\frac{1}{M}\right) A^{\frac{1}{M}} f(t)^{-\frac{1}{M}}-1=0 \leftrightarrow f(t)^{-\frac{1}{M}} \\
=\frac{M}{(M-1)} A^{\frac{1}{M}} .
\end{gathered}
$$

Therefore the inflection point is

$$
f(t)=A\left(1-\frac{1}{M}\right)^{M}
$$

Subsequently, we replace $f(t)$ by its formula to find the date corresponding to the inflexion point

$$
\mathrm{A}\left(1-\frac{1}{\mathrm{M}}\right)^{\mathrm{M}}=\mathrm{A}\left(1-\mathrm{e}^{-\mathrm{K}\left(\mathrm{t}-\mathrm{t}_{\mathrm{i}}\right)}\right)^{\mathrm{M}} .
$$

That implies that

$$
1-\frac{1}{M}=1-\mathrm{e}^{-\mathrm{K}\left(\mathrm{t}-\mathrm{t}_{\mathrm{i}}\right)} .
$$

This implies that

$$
\mathrm{t}=\frac{1}{\mathrm{~K}} \ln \mathrm{M}+\mathrm{t}_{\mathrm{i}}
$$

\subsection{Von Bertalanffy Function}

The function of Von Bertalanffy is defined as

$$
f(t)=A\left(1-B e^{-K t}\right)^{3}
$$

First adaptation of the model:

By replacing the parameter $\mathrm{M}$ by 3 at the level of the function of Richards, we obtain the following equations

$$
f(t)=A\left(1-B^{1-\frac{t}{t_{i}}}\right)^{3}
$$

First derivation of $\mathrm{f}(\mathrm{t})$

$$
\begin{aligned}
& f^{\prime}(t)=3 \frac{\ln B}{t_{i}} f(t)\left[\left(\frac{f(t)}{A}\right)^{-\frac{1}{3}}-1\right] . \\
& f^{\prime}(t)=3 \frac{\ln B}{t_{i}}\left(A^{\frac{1}{3}} f(t)^{\frac{2}{3}}-f(t)\right)
\end{aligned}
$$

Second derivation of $\mathrm{f}(\mathrm{t})$

$$
\begin{gathered}
f^{\prime \prime}(t)=\frac{\ln B}{t_{i}} f^{\prime}(t)\left(2 A^{\frac{1}{M}} f(t)^{-\frac{1}{3}}-3\right) . \\
f^{\prime \prime}(t)=3\left(\frac{\ln B}{t_{i}}\right)^{2}\left(2 A^{\frac{2}{3}} f(t)^{\frac{1}{3}}-5 A^{\frac{1}{3}} f(t)^{\frac{2}{3}}+3 f(t)\right)
\end{gathered}
$$

Calculation of the inflection point Quand

$$
f^{\prime \prime}(t)=0 f(t)=\frac{8}{27} A
$$

And

$$
t=t_{i} \frac{\ln 3 B}{\ln B}
$$

\begin{tabular}{|c|c|c|c|c|}
\hline Model name & Mathematical expression $\mathrm{f}(\mathrm{t})$ & Inflexion Point & Inflexion Age & Growth rate f'(t) \\
\hline Richards & $A\left(1-B e^{-K t}\right)^{M}$ & $\mathrm{~A}\left(1-\frac{1}{\mathrm{M}}\right)^{\mathrm{M}}$ & $\frac{\ln \mathrm{MB}}{\mathrm{K}}$ & $M K f(t)^{\left(1-\frac{1}{M}\right)}\left(A^{\frac{1}{M}}-f(t)^{\frac{1}{M}}\right)$ \\
\hline Richards (1) & $A\left(1-B^{1-\frac{t}{t_{i}}}\right)^{M}$ & $\mathrm{~A}\left(1-\frac{1}{\mathrm{M}}\right)^{\mathrm{M}}$ & $t_{i} \frac{\ln M B}{\ln B}$ & $M \frac{\ln B}{t_{i}}\left[A^{\frac{1}{M}} f(t)^{\left(1-\frac{1}{M}\right)}-f(t)\right]$ \\
\hline Richards (2) & $A\left(1-e^{-K\left(t-t_{i}\right)}\right)^{M}$ & $\mathrm{~A}\left(1-\frac{1}{\mathrm{M}}\right)^{\mathrm{M}}$ & $\frac{1}{\mathrm{~K}} \ln \mathrm{M}+\mathrm{t}_{\mathrm{i}}$ & $M K\left[A^{\frac{1}{M}} f(t)^{\left(1-\frac{1}{M}\right)}-f(t)\right]$ \\
\hline Von Bertalanffy & $A\left(1-B e^{-K t}\right)^{3}$ & $\frac{8}{27} \mathrm{~A}$ & $\frac{\ln 3 B}{K}$ & $3 \mathrm{Kf}(\mathrm{t})^{\frac{2}{3}}\left(\mathrm{~A}^{\frac{1}{3}}-\mathrm{f}(\mathrm{t})^{\frac{1}{3}}\right)$ \\
\hline
\end{tabular}

Second adaptation of the model:

$$
f(t)=A\left(1-e^{-K\left(t-t_{i}\right)}\right)^{3}
$$

First derivation of $\mathrm{f}(\mathrm{t})$

$$
f^{\prime}(t)=3 K\left(A^{\frac{1}{3}} f(t)^{\frac{2}{3}}-f(t)\right)
$$

Second derivation of $\mathrm{f}(\mathrm{t})$

$$
\begin{gathered}
f^{\prime \prime}(t)=3 K f^{\prime}(t)\left(\frac{2}{3} A^{\frac{1}{3}} f(t)^{-\frac{1}{3}}-1\right) . \\
f^{\prime \prime}(t)=9 K^{2}\left(\frac{2}{3} A^{\frac{2}{M}} f(t)^{\frac{1}{3}}-\frac{5}{3} A^{\frac{1}{3}} f(t)^{\frac{2}{3}}+f(t)\right)
\end{gathered}
$$

Calculation of the inflection point When

$$
f^{\prime \prime}(t)=0 f(t)=\frac{8}{27} A
$$

and

$$
\mathrm{t}=\frac{1}{\mathrm{~K}} \ln 3+\mathrm{t}_{\mathrm{i}}
$$

Table 2. Models of Richards and Von Bertalanffy with their adaptations. 


\begin{tabular}{lllll}
\hline Model name & Mathematical expression $\mathbf{f}(t)$ & Inflexion Point & Inflexion Age & Growth rate $\mathrm{f}^{\prime}(\mathrm{t})$ \\
\hline Von Bertalanffy (1) & $\mathrm{A}\left(1-\mathrm{B}^{1-\frac{\mathrm{t}}{\mathrm{t}_{\mathrm{i}}}}\right)^{3}$ & $\frac{8}{27} \mathrm{~A}$ & $\mathrm{t}_{\mathrm{i}} \frac{\ln 3 \mathrm{~B}}{\ln \mathrm{B}}$ & $3 \frac{\ln \mathrm{B}}{\mathrm{t}_{\mathrm{i}}}\left(\mathrm{A}^{\frac{1}{3}} \mathrm{f}(\mathrm{t})^{\frac{2}{3}}-\mathrm{f}(\mathrm{t})\right)$ \\
Von Bertalanffy (2) & $\mathrm{A}\left(1-\mathrm{e}^{-\mathrm{K}\left(\mathrm{t}-\mathrm{t}_{\mathrm{i}}\right)}\right)^{3}$ & $\frac{8}{27} \mathrm{~A}$ & $\frac{1}{\mathrm{~K}} \ln 3+\mathrm{t}_{\mathrm{i}}$ & $3 \mathrm{~K}\left(\mathrm{~A}^{\frac{1}{3}} \mathrm{f}(\mathrm{t})^{\frac{2}{3}}-\mathrm{f}(\mathrm{t})\right)$ \\
\hline
\end{tabular}

$t_{i}=-150$ days for sheep and -370 days for cattle.

\subsection{Function Gompertz}

$$
f(t)=A e^{-B e^{-K t}}
$$

Since $\mathrm{e}^{-\mathrm{Be}^{-\mathrm{Kt}}}$ and $\mathrm{A}$ are strictly positive, the Gompertz function is never cancelled and therefore the conception date $t_{i}$ does not exist for this function.

\subsection{Fonction Logistic}

$$
f(t)=\frac{A}{\left(1+B e^{-K t}\right)}
$$

Because $\mathrm{e}^{-\mathrm{Kt}}, \mathrm{B}$ and $\mathrm{A}$ are strictly positive, the Logistic function is never cancelled and therefore the conception date $\mathrm{t}_{\mathrm{i}}$ does not exist for this function.

\section{Comparison Between the Richards Model and Its Adaptations Applied to Sheep}

For example, adjusting the data for the Moroccan sheep breed "sardi", for weights at the typical age (birth, 10, 30, 90 and 480 days) for both sexes, to Richards model and his adaptations, whose properties are shown in Table 3, show that for the initial Richards model, design dates are -24.07 days and -23.6 days respectively for males and females (Figure 1). While the modified models, whose results are similar, have design dates ti of -150 days for both sexes.

Therefore, these adaptations of Richards model seem to be better adapted for animal species rather than the initial model.

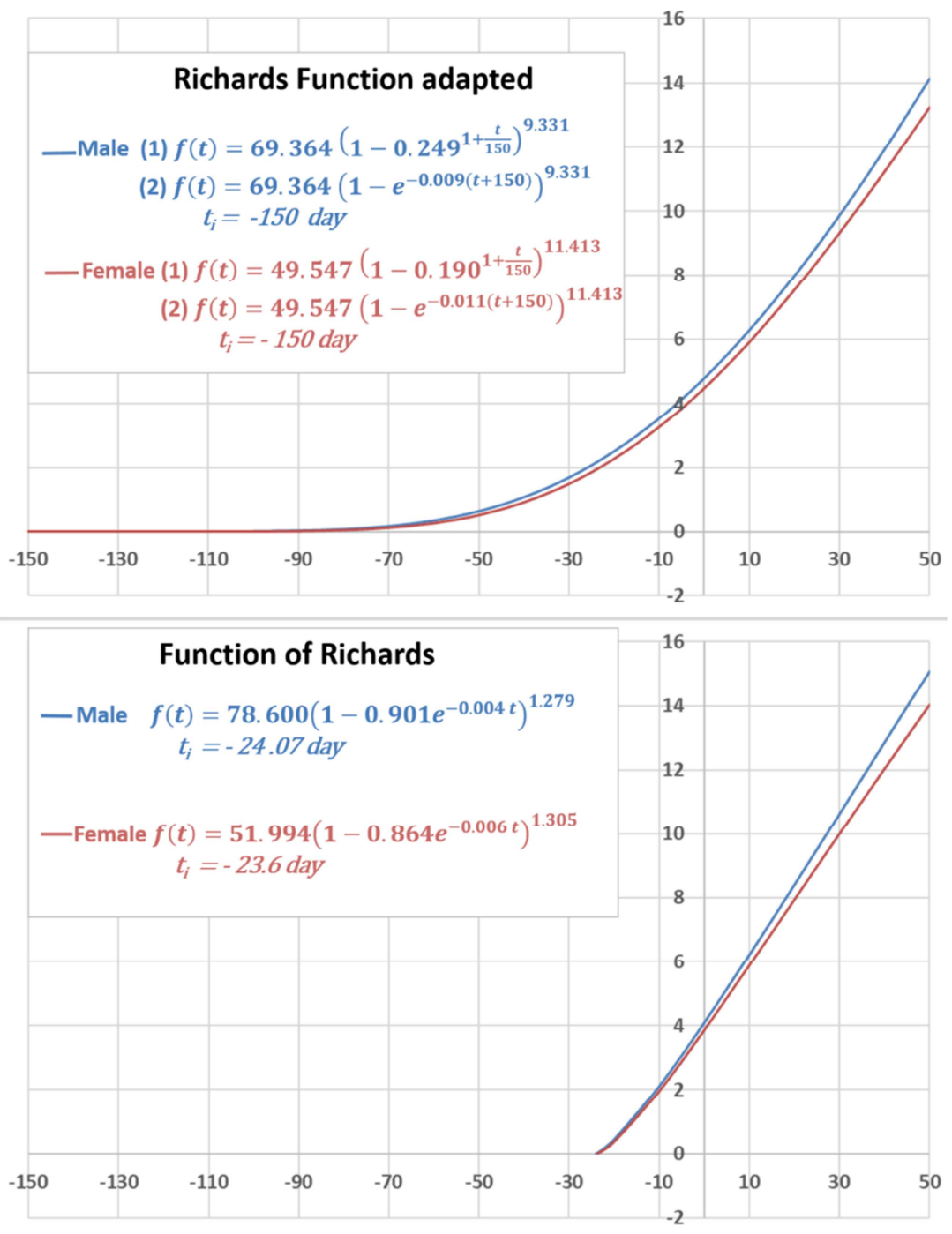

Figure 1. Comparison between the Richards Model and its adaptations applied to sheep. 
Table 3. Richards models and adaptations applied to sheep.

\begin{tabular}{lllll}
\hline Model name & Mathematical expression $\mathrm{f}(\mathrm{t})$ & Inflexion Point & Inflexion Age & Growth rate $\mathrm{f}^{\prime}(\mathrm{t})$ \\
\hline Richards & $\mathrm{A}\left(1-\mathrm{B} \mathrm{e}^{-\mathrm{K} t}\right)^{\mathrm{M}}$ & $\mathrm{A}\left(1-\frac{1}{\mathrm{M}}\right)^{\mathrm{M}}$ & $\frac{\ln \mathrm{MB}}{\mathrm{K}}$ & $\mathrm{M} \mathrm{K} \mathrm{f}(\mathrm{t})^{\left(1-\frac{1}{\mathrm{M}}\right)}\left(\mathrm{A}^{\frac{1}{\mathrm{M}}}-\mathrm{f}(\mathrm{t})^{\frac{1}{\mathrm{M}}}\right)$ \\
Richards 1 & $\mathrm{A}\left(1-\mathrm{B}^{1+\frac{\mathrm{t}}{150}}\right)^{\mathrm{M}}$ & $\mathrm{A}\left(1-\frac{1}{\mathrm{M}}\right)^{\mathrm{M}}$ & $-150 \frac{\ln \mathrm{MB}}{\ln \mathrm{B}}$ & $\mathrm{M} \frac{\ln \mathrm{B}}{-150}\left[\mathrm{~A}^{\frac{1}{\mathrm{M}}} \mathrm{f}(\mathrm{t})^{\left(1-\frac{1}{\mathrm{M}}\right)}-\mathrm{f}(\mathrm{t})\right]$ \\
Richards 2 & $\mathrm{A}\left(1-\mathrm{e}^{-\mathrm{K}(\mathrm{t}+150)}\right)^{\mathrm{M}}$ & $\mathrm{A}\left(1-\frac{1}{\mathrm{M}}\right)^{\mathrm{M}}$ & $\frac{1}{\mathrm{~K}} \ln \mathrm{M}-150$ & $\mathrm{M} \mathrm{K}\left[\mathrm{A}^{\frac{1}{\mathrm{M}}} \mathrm{f}(\mathrm{t})^{\left(1-\frac{1}{\mathrm{M}}\right)}-\mathrm{f}(\mathrm{t})\right]$ \\
\hline
\end{tabular}

\section{Conclusions}

After studying the adaptation of nonlinear mathematical models to take into consideration the date of conception of the animal species, only Richards and Von Bertalanffy could be adapted according to two methods to answer the aforementioned objective of the fact that logistic and Gompertz models are strictly positive and do not cancel each other out. The inflection point formulas and their corresponding growth function values were calculated for each of the adapted growth models. These formulas have statistical and biological interests. In addition, the comparison example between Richards' Model and its adaptations to sheep data shows that for the initial model, the design dates are -24.07 days and -23.6 days for males and females, respectively. that the modified models, whose adjustment results show similar results, have -150 day design dates for both sexes. Therefore, the modified models of Richards and Von Bertalanffy best represent the biology of animal species and could replace the initial nonlinear functions for future growth modeling studies regardless of the animal species studied.

\section{References}

[1] Patricia Román-Román, Juan José Serrano-Pérez and Francisco Torres-Ruiz (2019). A Note on Estimation of MultiSigmoidal Gompertz Functions with Random Noise. $\begin{array}{lllll}\text { Mathematics } & 2019, & 7 & \text { (6), }\end{array}$ https://doi.org/10.3390/math7060541.

[2] Irfan Daskiran et al. Growth caractéristics of indigenous Norduz female and male lambs. J. of Agricutural sciences (2010), v. 16, p. 62-69. Turkey.

[3] Benjamin Gompertz. On the nature of the function of the law of human mortality, and on a new mode of determining the value of life contingencies. Philosophical transactions of the Royale Society of London. v. 115. (1825) p 513. 583.

[4] Samuel Brody, 1945. Bioenergetics and Growth with special reference to the efficiency complex in domestic animals. Hafner publishing company (1945) Inc. New York 3. N. Y.
[5] Ludwig von Bertalanfy. Quantitative lawsin metabolism and Growgh. The quarterly revew of biology (1957) vol. $32 n^{\circ} 3$.

[6] Fitzhugh Jr HA. Analysis of growth curves and strategies for altering their shape. J Anim Sci 1976; 42: 1036-1051.

[7] Firat MZ, Karaman E, Basar EK, Narinc D. 2016. Bayesian analysis for the comparison of nonlinear negression model parameters: an application to the growth of Japanese quail. Braz J Poultry Sci. 18 (SI): 19-26.

[8] Bathaei SS, Leroy PL. Growth and mature weight of Mehraban Iranian fat-tailed sheep. Small Rumin Res 1996; 22: 155-162.

[9] Freitas AR. Curvas de crescimento na producão animal. R Bras Zootec 2005; 34: 786795.

[10] Sariyel V, Aygun A, Keskin I. 2017. Comparison of growth curve models in partridge. Poult Sci. 96 (6): 1635-1640.

[11] Yaya Wen, Ke Liu, Honghua Liu, Haiyue Cao, Haiguang Mao, Xinyang Dong \& Zhaozheng Yin (2019) Comparison of nine growth curve models to describe growth of partridges (Alectoris chukar), Journal of Applied Animal Research, 47: 1, 195-200, DOI: 10.1080/09712119.2019.1599900.

[12] J. C Pinheiro and D. M. Bates, Mixed-Effects Models in S and S-PLUS, Springer-Verlag, NewYork, 2000.

[13] Nelder, J. A., "The fitting of a generalization of the logistic curve”, Biometrics Vol. 17 (1961), 89-110.

[14] Winsor, C. P., "The Gompertz curve as a growth curve", Proc. National Academy of Science, Vol. 18 (1932), No. 1.

[15] Richards, F. J., "A flexible growth function for empirical use”, J. Exp. Bot. Vol. 10 (1959), 290-300.

[16] Bertalanffy, von L., "Quantitative laws in metabolism and growth”, Quart. Rev. Biol. Vol. 3 (1957), No. 2, 218.

[17] Brown, J. E., Fitzhugh Jr., H. A. and Cartwright, T. C. A Comparison of Non Linear 1976.

[18] Malhado, C. H. M., Carneiro, P. L. S., Affonso, P. R. A. M., Souza Jr., A. A. O. and Sarmento, J. L. R.. Growth Curves in Dorper Sheep Crossed with the Local Brazilian Breeds, Morada Nova, Rabo Largo, and Santa Inês. Small Rumin. Res. 2009, 84: 16-21. 